\title{
Citotoxicidade de plantas com indicativo etnográfico para a desinfecção de água
}

\author{
GONÇALVES, A.R. ${ }^{1^{*}}$; WIEST, J.M. ${ }^{2,3}$; ROEHE, P.M. ${ }^{2}$; CARVALHO, H.H. ${ }^{3}$ \\ ${ }^{1}$ Departamento de Veterinária Preventiva/Faculdade de Veterinária / Universidade Federal de Pelotas (UFPel), \\ Baronesa Capão do Leão Campus Universitário, * aspereza@ig.com.br; ${ }^{2}$ Programa de Pós-graduação em Ciências \\ Veterinárias / Faculdade de Veterinária/Universidade Federal do rio Grande do Sul (UFRGS) ${ }^{3}$ Instituto de Ciência \\ e Tecnologia de Alimentos/Universidade Federal do Rio Grande do Sul
}

\begin{abstract}
RESUMO: Aágua para o consumo humano e animal é um patrimônio cada vez mais escasso que é necessário preservar. O processo de desinfecção utilizado atualmente tem como base desinfetantes clorados, que em combinação com resíduos orgânicos, resultam em trihalometanos (potencialmente oncogênicos). A proposta deste trabalho foi avaliar a citotoxicidade de cinco extratos de plantas, capazes de promover desinfecção da água, frente a seis linhagens celulares, a saber: Vero (ATCC CCI81) African green monkey cells; MDBK (ATCC CCL 24) Martin Darby Bonne Kidney cells; MDCK (ATCC CCL 34) Canis familiaris kidney cells; CRFK (ATCC CCL 94) Felix catus kidney cells; PK 15 (ATCC CCL33) Sus scrofa kidney cells; RK13 (ATCC CCL37) Orytolagus cuniculus Kidney cells, e avaliar cultivos celulares mais sensíveis para o teste de toxicidade de extratos de plantas. Destes extratos, o mais tóxico foi o de Erva de Formigueiro (Chenopodium álbum) diante de todas as células testadas. O extrato de chapéu de couro (Sagittaria montevidensis) foi medianamente tóxico e os demais baleeira (Cordia curassavica), folha da fortuna (Bryophyllum pinnatum[Kurz]) e sete sangrias (Cuphea carthagenensis [Jacq.] J.F. Macbride) foram os menos tóxicos. Este resultado foi estatisticamente significativo $(p=0,99)$, quando se comparou o extrato das plantas frente às concentrações e às células estudadas. Entre as células utilizadas, as mais sensíveis foram a VERO (rim de macaco) e a CRFK (rim de gato) quando comparadas com as demais foram (MDBK, MDCK, PK 15, RK 13), com diferença significativa $(p=0,99)$. Conclui-se que há necessidade de serem avaliados os extratos vegetais quanto a toxicidade, antes do emprego como recursos de saúde, e que algumas células são mais eficazes que outras na detecção de efeito citopatogênico.
\end{abstract}

Palavras-chave: citoxicidade, Chenopodium, Sagittaria, Cordia, Bryophyllum, Cuphea

\begin{abstract}
Cytotoxicity of plants as an ethnographic indicator for water disinfection. Freshwater for human and animal consumption is an increasingly rare patrimony that needs to be preserved. The currently adopted disinfection process uses chloride disinfectants which, combined with organic residues, result in trihalomethane (potentially oncogenic). The aim of this work was to evaluate the cytotoxicity of five plant extracts, capable of promoting water disinfection, against six cell lines: Vero (ATCC CCl81) African green monkey cells; MDBK (ATCC CCL 24) Martin Darby Bonne kidney cells; MDCK (ATCC CCL 34) Canis familiaris kidney cells; CRFK (ATCC CCL 94) Felix catus kidney cells; PK 15 (ATCC CCL 33) Sus scrofa kidney cells; RK13 (ATCC CCL 37) Oryctolagus cuniculus kidney cells, as well as to evaluate the most sensitive cell cultures for the toxicity test of plant extracts. The most toxic extract was that of white goosefoot (Chenopodium album) against all tested cells. California arrowhead (Sagittaria montevidensis) extract had median toxicity and extracts of "erva baleeira" (Cordia curassavica), miracle leaf (Bryophyllum pinnatum [Kurz]) and colombian waxweed (Cuphea carthagenensis [Jacq.] J.F. Macbride) were the least toxic. This finding was statistically significant $(p=0.99)$ when the plant extracts were compared regarding the concentrations and the studied cells. The most sensitive cells were VERO (monkey kidney) and CRFK (feline kidney) compared to the others (MDBK, MDCK, PK 15, RK 13), with significant difference $(p=0.99)$. In conclusion, plant extracts must be evaluated as to their toxicity before being used as health resources and some cells are more effective than others in the detection of cytopathogenic effects.
\end{abstract}

Key words: cytotoxicity, Chenopodium, Sagittaria, Cordia, Bryophyllum, Cuphea

Recebido para publicação em 01/08/2008

Aceito para publicação em 16/03/2009

Rev. Bras. PI. Med., Botucatu, v.11, n.3, p.305-309, 2009. 


\section{INTRODUÇÃO}

Em 2003, a Unesco divulgou ranking de cento e oitenta paises, indicando o Brasil como o 250 colocado quanto a disponibilidade de água per capita com $48.314 \mathrm{~m}^{3}$ ano $^{-1}$ (UNESCO, 2005). Esta situação é motivada pela má distribuição dos recursos hídricos, pois $80 \%$ da água existente no Brasil está localizada na região amazônica, onde vive $5 \%$ da população. O nordeste brasileiro, abrangendo $1 / 3 \mathrm{da}$ população, possui somente 3,3\% da água encontrada no país (Rainho, 1999).

A despeito desta discrepância na relação distribuição e usuários, os recursos hídricos são o destino de grande quantidade de resíduos, que contribuem significativamente para a poluição e contaminação (Perdomo, 1996; Mertem \& Minella, 2002; Garcia, 2003).

O cloro, apesar de apresentar risco potencial no desenvolvimento de tumores pela formação de trihalometanos vem sendo empregado como o principal agente para a desinfecção de água (Macedo, 2001a; 2001b).

No estudo de plantas medicinais por indicativo etnográfico é importante a determinação do efeito tóxico destes extratos sobre organismos vivos (Devienne et al., 2004; Fonte et al., 2004). Na pesquisa científica os diagnósticos e as alterações teciduais são realizados, baseado em testes que buscam a eficiência, eficácia e efetividade (Pereira, 1995). Fontes (2001) relata a possibilidade da utilização de cultivos unicelulares considerando que a toxicidade das substâncias químicas, que se verifica in vivo, é um processo que ocorre a nível celular e que assim pode ser estudado in vitro.

O objetivo deste trabalho foi avaliar a citotoxicidade de diferentes diluições de extrato bruto de cinco plantas com indicativo etnográfico para a desinfecção de água, frente a seis linhagens de células de origem renal bem como avaliar qual delas seria a mais sensível ao efeito tóxico dos extratos de plantas.

\section{MATERIAL E MÉTODO}

\section{Extratos vegetais}

Tendo como base os resultados de Gonçalves (2005) que determinou in vitro atividade bactericidia ou bacteriostasia de extratos de dezenove plantas com indicativo etnográfico para a desinfecção de água sobre Staphylococcus aureus (ATCC 25923), Escherichia coli (ATCC11229), Salmonella Enteritidis (ATCC 11076) e Enterococcus faecalis (ATCC 19433), Neste tabalho foram selecionadas para testes in vitro de citotoxicidade, cinco destas plantas, que se destacaram pela inibição bacteriana demonstrada, quais sejam: baleeira (Cordia curassavica [Jacq.]
Adem \& Schult), chapéu de couro (Sagittaria montevidensis Cham. et Schlecht.), folha da fortuna (Bryophyllum pinnatum, Kurz), sete sangrias (Cuphea carthagenensis [Jacq.] Macbride) e erva de formigueiro (Chenopodium album L.). As respectivas excicatas destas plantas, organizadas segundo Ming (1996), foram devidamente encaminhadas para registro e depósito no Herbário do Departamento de Botânica, do Instituto de Ciências Biológicas da UFRGS em Porto Alegre, RS.

Talos, folhas e flores recém colhidos destas cinco espécies foram triturados grosseiramente e colocados em álcool etílico de cereais a 96 $\mathrm{GL}$, na proporção de $400 \mathrm{~g}$ de planta para $1000 \mathrm{~mL}$ de álcool, num período mínimo de 15 dias para a extração hidroalcoólica (Farmacopéia, 1959). Após esse período, foram submetidos à destilação fracionada sob pressão reduzida em rota-vapor, desprezandose a porção alcoólica com posterior re-hidratação asséptica, restabelecendo-se as concentrações iniciais dos extratos vegetais (Avancini, 2002).

\section{Células}

As linhagens celulares utilizadas para o teste de citotoxicidade foram:

- Vero (ATCC CCI81) African green monkey cells;

Kidney cells;

- MDBK(ATCC CCL24) Martin Darby Bonne kidney cells;

- MDCK (ATCC CCL 34) Canis familiaris

- CRFK (ATCC CCL 94) Felix catus kidney cells;

- K 15 (ATCC CCL 33) Sus scrofa kidney

cells; Kidney cells.

- RK13 (ATCC CCL 37) Orytolagus cuniculus

As monocamadas celulares foram cultivadas, segundo Montanha et al. (1995), em triplicata, placas com 96 poços, que foram inoculados com $50 \mu \mathrm{L}$ de Meio Mínimo Essencial (MEM), adicionado de 10\% de soro fetal bovino, acrescido de 160 unidades $\mathrm{mL}^{-1}$ de penicilina e $80 \mathrm{mg} \mathrm{mL}^{-1}$ de gentamicina, em concentração mínima de 50.000 células $\mathrm{mL}^{-1}$.

Após incubação a $37^{\circ} \mathrm{C}$ em estufa de $10 \%$ CO2, o tapete celular era observado por 48 horas e quando completo era submetido ao teste de citotoxicidade frente a diluições do extrato.

\section{Teste de citotoxicidade}

Após estabelecidos os tapetes celulares, as microplacas foram divididas em duas, cada metade destinada a uma planta, inoculadas com concentrações de 10, 5, 4, 3, 2 e 1\% de seu extrato bruto, em 4 poços por concentração. Maiores concentrações foram testadas, preliminarmente, em triagem com as doses de $50,40,30,25,20,15,10$ e $5 \%$. Os 48 poços 
remanescentes foram destinados como controle da célula, utilizando-se o mesmo meio. Após 24 horas, as placas foram observadas em microscópio para identificação de alterações na estrutura celular como arredondamento, picnose, morte celular com descolamento no tapete. Nos casos duvidosos, o tapete celular foi corado pelo Azul de Trypan para a confirmação da morte celular, sendo considerado positivo,a coloração de mais de $50 \%$ do tapete (Montanha et al., 1995).

A Intensidade de Concentração Máxima não Citopatogênica (ICMnC) foi relacionada a variáveis ordinais arbitrárias que assumiram valores de 1 a 6 , dando subsídios para o entendimento da Tabela 1. Desta forma, o valor 6 (seis) representa ICMnC do extrato à $10 \%$; o valor 5 (cinco) representa ICMnC à $5 \%$; o valor 4(quatro) ICMnC à $4 \%$; os valores $3,2 \mathrm{e}$
1 , assim sucessivamente, representam as concentrações de $3,2 \mathrm{e} 1 \%$, respectivamente, enquanto valor 0 (zero) representa a presença de atividade citotóxica em concentrações abaixo de $1 \%$.

A análise estatística se fez através de análise de variância, seguida pelo Teste de Duncan, quando se comparou o extrato das plantas frente às concentrações e a todas as células em estudo.

\section{RESULTADO E DISCUSSÃO}

Pela Tabela 1, observa-se que erva de formigueiro (Chenopodium album), mesmo na concentração mais baixa (1\%), apresentou efeito citotóxico (Tabela 1), confirmado estatísticamente $(p=0,99)$. Este dado mostra o risco de se usar esta planta como antibacteriano na desinfecção de água.

TABELA 1. Concentrações Máximas não Citopatogênicas de cinco extratos de plantas com indicativo etnográfico para desinfecção de água, frente ao cultivo de seis linhagens diferentes de células, determinadas em doze repetições.

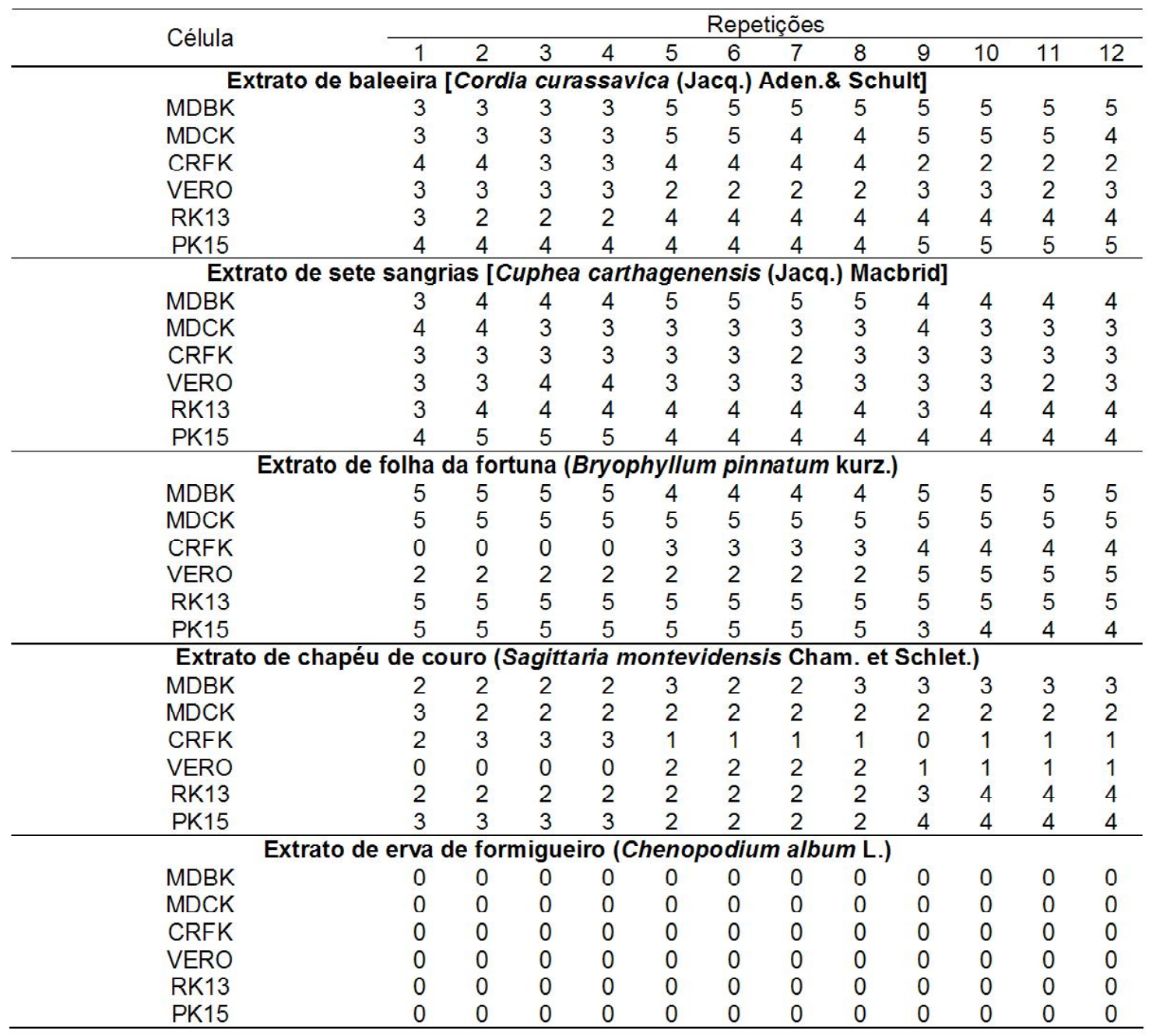

Vero (ATCC CCl81) African green monkey cells; MDBK (ATCC CCL 24) Martin Darby Bonne Kidney cells; MDCK (ATCC CCL 34) Canis familiaris kidney cells; CRFK (ATCC CCL 94) Felix catus kidney cells; PK 15 (ATCC CCL 33) Sus scrofa kidney cells; RK13 (ATCC CCL 37) Orytolagus cuniculus Kidney cells. 
A bibliografia confirma o resultado obtido, uma vez que Chenopodium ambrosioides, pertencente ao mesmo gênero é considerado tóxico e indicado como ectoparasiticida (Lorenzi \& Matos, 2002). Entretanto, o extrato de chapéu de couro (Sagittaria montevidensis) apresentou repetições que foram tóxicas em concentrações inferiores a 1\%, bem como, outras não foram tóxicas em concetrações de até $4 \%$. Observa-se que no teste em células VERO, o extrato foi mais citopatogênico que nas demais celulas, sendo seguida pela CRFK. Esta observação remete a imaginar que talvez estas células sejam mais sencíveis a este extrato, o que carece de maiores observações. Mesmo assim, o emprego de extratos de chapéu de couro em hidrodesinfecção exige cuidados, desaconselhando seu uso.

Os demais extratos baleeira (Cordia curassavica); folha da fortuna (Bryophyllum pinnatum [Kurz]) e sete sangrias (Cuphea carthagenensis [Jacq.] J.F. Macbride) apresentaram efeito não citopatogênico em concentrações entre 2 e $5 \%$ e não tiveram diferenças de não toxicidade significativa $(p=0,95)$ entre si, mostrando a possibilidade de uso como desinfetantes hídricos nessas dosagens. $O$ extrato de Bryophyllum pinnatum (Kurz) em um dos testes com quatro repetições apresentou escore "0" o que significaria efeito citopatogênico abaixo de $1 \%$ , este achado o colocaria como bastante tóxico, mas nas outras repetições seu escore subiu para 3 e 5 na CRFK (célula de rim de gato) o que lhe garantiu lugar entre os extratos menos tóxicos em estudo.

Baseados nestes dados observa-se que não houve repetitividade no escore zero tendo os demais escores permanecido entre 3 e 4 . Apesar da folha da fortuna apresentar ICMnC entre 3 e 4 nas últimas repetições, o valor zero para a célula CRFK desabilita seu uso .

A citotoxicidade in vitro é usada para definir o efeito tóxico basal, como por exemplo, a capacidade da substância de causar dano nas funções básicas da célula levando à morte celular (Eisembrand, et al., 2002). Os autores afirmam ainda que, para o aprimoramento do teste de citotoxicidade, deve ser levado em conta o órgão alvo do efeito citopático in vivo com a escolha das linhagens celulares compatíveis com o referido órgão. Neste trabalho, por sua relação com a eliminação hídrica, foram utilizados seis cultivos de linhagem de células renais de diversas espécies mamíferas.

Os resultados permitem uma avaliação da sensibilidade de cada linhagem celular frente aos extratos das cinco plantas em teste. Destas células, as mais sensíveis foram a VERO (rim de macaco) e a CRFK (rim de gato), as quais não apresentaram diferença significativa entre si. As demais foram menos sensíveis, com diferença significativa $(p=0,99)$ pelo teste de DUNCAN.

\section{CONCLUSÃO}

Conforme os resultados obtidos, mesmo havendo evidências de atividade antibacteriana, fica evidenciada a necessidade de serem avaliados os extratos vegetais quanto a sua toxicidade, antes de seu emprego como recursos de saúde.

Pode-se constatar que algumas células são mais eficazes que outras na detecção de efeito citopatogênico. Com base nestes dados, percebese a necessidade de maior conhecimento dessas linhagens celulares e de confrontá-las quanto à sensibilidade aos produtos tóxicos, levando em consideração o órgão alvo.

\section{AGRADECIMENTO}

A Ydersio Vianna pela análise estatística, a Mariel Bizarro e Veridiana Gonçalves Bizarro pela montagem do trabalho.

\section{REFERÊNCIA}

AVANCINI, C.A.M. Saneamento aplicado em saúde e produção animal: etmografia, triagem da atividade antibacteriana das plantas nativas no Sul do Brasil e testes de avaliação do decocto de Hypericum caprifobatum Cham. E. Schlecht - Hypericacea (Gietiferal) - ("Escadinha / sinapismo") para uso como desinfetante antisséptico. 2002. 309p. Tese (Doutorado em Ciência Veterinárias) Universidade Federal do Rio Grande do Sul, Porto Alegre. DEVIENNE, K.F.; RADDI, M.S.G.; POZETTI, G.L. Das plantas medicinais aos fitofármacos. Revista Brasileira de Plantas Medicinais, v.6, n.3, p.11-4, 2004.

EISEMBRAND, G. et al. Methode of in vitro toxicology. Food and Chemical Toxicology, v.40, n.1, p.193-236, 2002.

FARMACOPEIA dos Estados Unidos do Brasil. 2.ed. São Paulo: Siqueira, 1959. 1265p.

FONTE, N.N.; CAVALET, V.J.; BIASI, L.A. A complexidade do trabalho com plantas medicinais. Revista Brasileira de Plantas Medicinais, v.7, n.1, p.16-22, 2004.

FONTES, M.E. Toxicologia. Lisboa: Seção de Farmacologia e Toxicologia, 2001. 11p.

GARCIA, R. Sede Global. Galileu, n.140, p.43-54, 2003. GONÇALVES, A.R. Fitodesinfecção aplicada a águas na perspectiva da agricultura familiar. 2005. 130p. Dissertação (Mestrado em Ciências Veterinárias) Universidade Federal do Rio Grande do Sul, Porto Alegre. LORENZI, H.; MATOS, F.J.A. Plantas medicinais no Brasil: nativas e exóticas. Nova Odessa: Instituto Plantarum de Estudos da Flora, 2002. v.1, 512p.

MACEDO, J.A.B. Cloraminas, uma solução para evitar trihalometanos no processo de desinfecção de águas para abastecimento público. Higiene Alimentar, v.15, n.90, p.93-103, 2001a.

MACEDO, J.A.B. Águas \& Águas. São Paulo: Varela, 2001b. 505p.

MERTEM, G.H.; MINELLA, J.P. Qualidade da água em bacias hidrográficas rurais: um desafio atual para a sobrevivência futura. Agroecologia e Desenvolvimento Rural Sustentável, v.3, n.4, p.33-8, 2002. 
MING, L.C. Coleta de plantas medicinais. In: DISTASI, L.C. Plantas medicinais: arte e ciência: um guia para o estudo interdisciplinar. São Paulo: Ed. UNESP, 1996. p.69-86.

MONTANHA, J.A. et al. Anti-herpesvirus activity of aporphine alkaloids. Planta Médica, v.61, n.5, p.393-492, 1995.

PERDOMO, C.C. Impacto ambiental causado pelos dejetos de suínos. Informativo do Centro Nacional de
Pesquisa de Suínos e Aves, v.4, n.14, p.4, 1996. PEREIRA, M.B. Epidemiologia teórica e prática. Rio de Janeiro: Guanabara Kogan. 1995. 583p.

RAINHO, J.M. Planeta Água. Revista Educação, v.26, p.48-64,1999.

UNESCO. Water availability per person per year. Disponível em: <http://www.unesco.rog/bpi/wwdr/ WWDR_chart1.eng.pdf>. Acesso em: 21 fev. 2005. 